Geopolítica(s) Revista de estudios sobre espacio y poder ISSN: 2172-3958

https://dx.doi.org/10.5209/geop.69374

\title{
Revisitando Refuxios en tiempos de COVID-19
}

\author{
Carme Nogueira ${ }^{1}$
}

Recibido: 9 de mayo de 2020 / Aceptado: 10 de mayo de 2020

Resumen. La serie de intervenciones artísticas Refuxios prestaba atención al espacio público. Trataba de resistir la ilusión de la arquitectura moderna de producir espacios unificados, ordenados, programados, es decir, con un sentido muy concreto y unívoco de la funcionalidad. Se partía de la idea de que las necesidades de habitabilidad son, en realidad, anárquicas y cambiantes, como ha venido a mostrarnos el confinamiento en tiempos de COVID-19.

Palabras clave: pandemia de COVID-19; espacio público; intervenciones artísticas; arquitectura; confinamiento.

\section{[en] Revisiting Refuxios in the Time of COVID-19}

Abstract. The Refuxios series of artistic interventions paid attention to public space. It tried to resist the illusion of modern architecture of producing unified, ordered, programmed spaces, that is, with a very concrete and univocal sense of functionality. It started from the idea that habitability needs are, in reality, anarchic and changing, as the confinement in times of COVID-19 shows.

Keywords: COVID-19 pandemic; public space; artistic interventions; architecture; lockdown.

\section{[pt] Revisitando Refuxios em tempos da COVID-19}

Resumo. A série de intervenções artísticas Refuxios chamava atenção à problemática do espaço público. Buscava-se resistir à ilusão da arquitetura moderna para produzir espaços unificados, organizados e planejados, isto é, com um sentido de funcionalidade muito concreto e unívoco. Partia-se da ideia de que as necessidades de habitabilidade são, na realidade, anárquicas e mutáveis, como o confinamento nos tempos da COVID-19 nos mostrou.

Palavras-chave: pandemia da COVID-19; espaço publico; intervenções artísticas; arquitetura; confinamento.

Cómo citar: Nogueira, C. (2020). Revisitando Refuxios en tiempos de COVID-19. Geopolítica(s). Revista de estudios sobre espacio y poder, 11 (Especial), 319-321.

\footnotetext{
1 Artista.

E-mail: cn@cntxt.org
} 


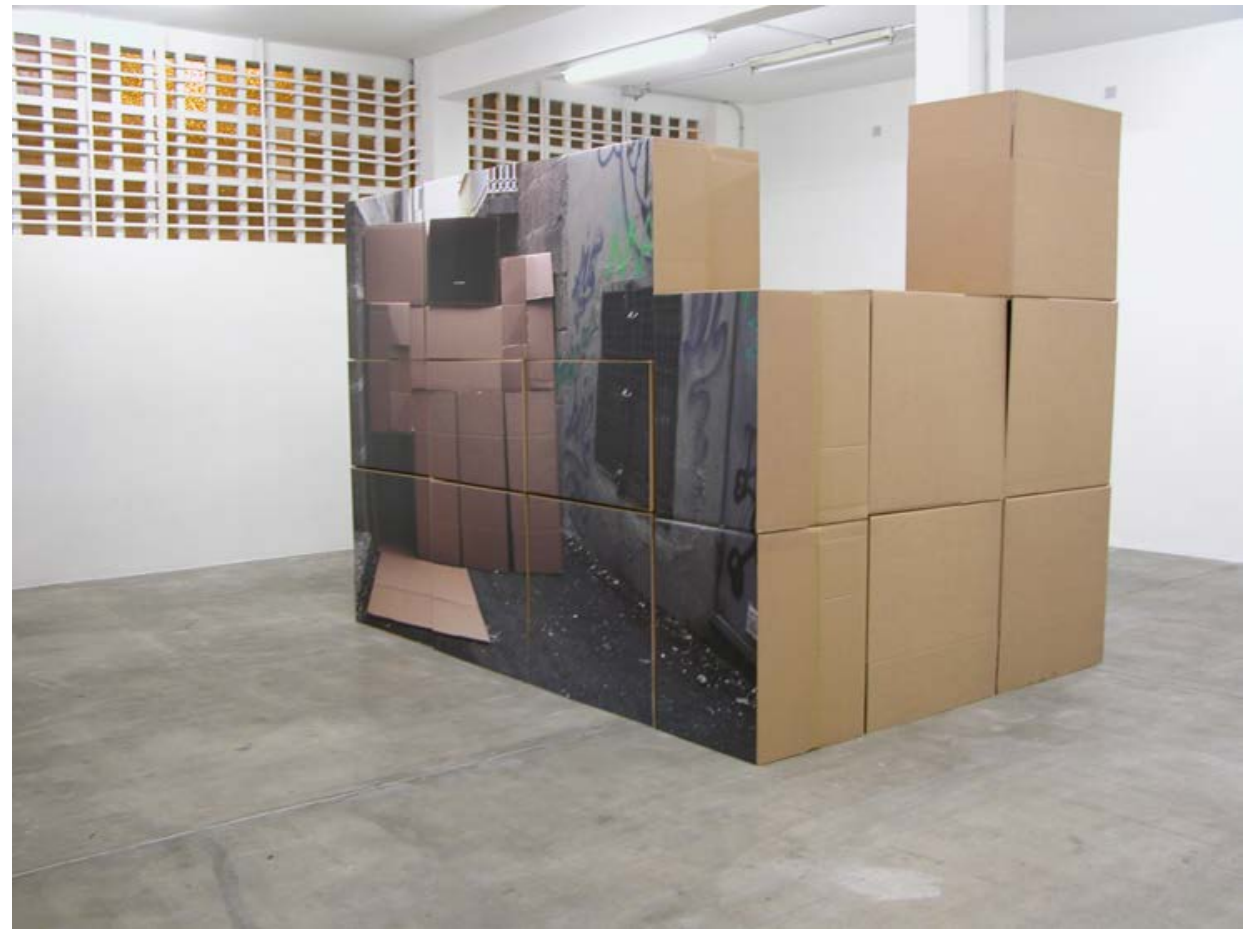


Cuando allá por el 2004 empecé trabajando con la serie Refuxios ponía mi atención en el espacio público. En realidad, en los diferentes espacios en los que ese espacio público, que pensábamos unificado, se desdoblaba. Pero entonces no podía imaginar los retos de pensar en el espacio público tras la pandemia del COVID-19.

En aquel momento definía esa serie de instalaciones como una forma de habitar, temporalmente, el espacio. El modo de comportarse, decía entonces, mostrarse, resistirse, crea espacios propios que no se pueden ver, pero que habitan el contexto. Incorporan actitudes que dan forma a un nuevo espacio, una forma de vivir que es, en cierto modo, un "refugio" en el espacio social. Estos "espacios personales" funcionan de un modo similar a esas formas de habitabilidad que hemos denominado arquitectura popular.

Esos nuevos espacios personales, tanto en la forma de refugios físicos como en las abstracciones de las respuestas emocionales, acaban influyendo en el espacio circundante de forma que varía su significado. Deconstruye su sentido. Del mismo modo que los refugios físicos niegan la ordenación del espacio, las reglas que intentan organizar, dar sentido, a un espacio organizado, también los refugios emocionales que nos construimos para defender una postura personal, mantener una distancia crítica, un lugar propio, transforman el contexto social en el que se ubican.

Ahora, como antes, tengo más confianza en esos modestos refuxios que en las grandes respuestas. Pero pienso en los retos a los que tendré que enfrentarme para seguir con mi trabajo, para seguir habitando un espacio público que creo común, que creo que se hace con la aportación de todas y la transformación continua... pero con una transformación física, con el contacto. Y me doy cuenta que podrán aparecer miedos con los que no contaba, refuxios que en lugar de acercarnos y ayudarnos a construir lugares problemáticos pero ricos, nos distancien. 